Ao iniciar esta pesquisa, uma das principais indagações defrontadas surgiu com relação ao proibitivo do artigo $7^{\circ}$, inciso XXXIII, da Constituição da República Federativa do Brasil de 1988, o qual pela literalidade entende que o trabalho realizado pelos menores de 16 (dezesseis) anos excepcionado na condição de menor aprendiz aos 14 (quatorze) anos de idade - é vedado.

No entanto, existem outros fundamentos normativos que parecem possibilitar o labor de crianças e adolescente em seguimentos artísticos, tal como a Convenção n. ${ }^{\circ}$ 138/73 da Organização Internacional do Trabalho, que apresenta a possibilidade de participação de crianças e adolescentes, mesmo aquelas menores de 16 (dezesseis) anos de idade, em representações artísticas.

Dessa forma, na essência, o que se tem hodiernamente é a conjugação de normas Internacionais - tal como a Convenção n. ${ }^{\circ}$ 138/73 da Organização Internacional do Trabalho - e normas nacionais, a exemplo, a Constituição da República Federativa do Brasil de 1988 e o Estatuto da Criança e do adolescente, para fundamentar a possibilidade do exercício do trabalho artístico aos menores de 16 (dezesseis) anos de idade.

Contudo, os casos fáticos postos como exemplo, envolvendo a realidade do exercício do trabalho infantil artístico - caso Maísa; Sandy; Felipe Paulino no filme "Cidade de Deus - permitem verificar as possíveis consequências e negligências que ocorrem, por esse motivo percebe-se que existem limitações e condições a serem seguidas nas expedições das autorizações. Tal como as disposições previstas no artigo 149, parágrafo $1^{\circ}$ do Estatuto da Criança e do Adolescente, bem como os princípios protetivos, dispostos no texto constitucional e nas legislações infraconstitucionais, que devem ser observados.

Constatou-se, ainda, que, com a Emenda Constitucional n. ${ }^{\circ}$ 45/2004, a competência para autorizações de participação de crianças e adolescentes em trabalhos artísticos é da Justiça do Trabalho, posição essa também defendida por Corrêa; Oliva e Arruda, e, consequentemente, não mais do juiz da Infância e da Juventude.

A criação de normas protetivas mescladas à observância da prioridade absoluta e da doutrina da proteção integral é necessária, mas não suficiente. Nesse caso, a regulamentação específica e detalhada versando sobre as peculiaridades do trabalho artístico infantil seria um passo essencial e relevante, eis que, é preciso haver a contínua busca pelo reconhecimento e proteção de direitos, porquanto eles não são garantidos ao homem ou pelo objeto a ser protegido de forma estanque ou sem variações, mas sim devem ser garantidos de forma gradual e variável.

Gradual, pois, sempre existirá a necessidade do reconhecimento de novos direitos, sendo, assim, variado conforme o destinatário, porque, enfatizando uma igualdade material, crianças e adolescentes possuem uma necessidade maior de proteção por estarem em patamar frágil. Tornandose, dessa forma, não só um dever familiar e moral a proteção destes, mas também, um dever social e 
estatal.

\section{REFERÊNCIAS}

BRASIL. Constituição da República Federativa do Brasil de 1988. Diário Oficial da República Federativa do Brasil, Brasília-DF, 05 outubro 1988. Disponível em: < http://www.planalto.gov.br /ccivil_03/constituicao/constituicao.htm>. Acesso em: 07 julho 2017.

CASSAR, Vólia Bomfim. Direito do trabalho. 3. ed. Niterói: Impetus, 2009.

CAVALCANTE, Sandra Regina. Trabalho infantil artístico: do deslumbramento à ilegalidade. Revista TST, Brasília, vol. 79, n 1, jan/mar 2013.

CORRÊA, Lélio Bentes; ARRUDA, Kátia Magalhães; OLIVA, José Roberto Dantas. O Juiz do Trabalho e a competência para autorizações do trabalho artístico de crianças e adolescentes. Revista do Tribunal Regional do Trabalho da $15^{\text {a }}$ Região, n. 47, 2015.

MARQUES, Rafael Dias. Trabalho infantil artístico: possibilidades e limites. Revista TST, Brasília, v.79, n 1, jan / mar 2013.

MARTINEZ, Luciano. Curso de direito do trabalho: relações individuais, sindicais e coletivas do trabalho. 2 ed. São Paulo: Saraiva, 2011.

MARTINS, Adalberto. A proteção constitucional ao trabalho de crianças e adolescentes. São Paulo: Ltr, 2002.

MARTINS, Sérgio Pinto. Direito do trabalho. 22 ed. São Paulo: Atlas, 2006.

MEDEIROS NETO, Xisto Tiago; MARQUES, Rafael Dias. Manual de atuação do ministério público na prevenção e erradicação do trabalho infantil. Brasília: CNMP, 2013.

MINHARRO, Erotilde. A criança e o adolescente no direito do trabalho. São Paulo: Ltr, 2013.

MORAES, Alexandre de. Direito constitucional. São Paulo: Atlas, 2014.

NASCIMENTO, Nilson de Oliveira. Manual do trabalho do menor. São Paulo: LTr, 2003.

NASCIMENTO, Amauri Mascaro. Curso de direito do trabalho. 26. ed. São Paulo: Saraiva, 2011.

NOCCHI, Andrea Saint Pastous; VELLOSO, Gabriel Napoleão; FAVA, Marcos Neves (Orgs.). Criança, adolescente, trabalho. São Paulo: Ltr, Anamatra, 2010.

PERES, Antonio Galvão; ROBORTELLA, Luiz Carlos Amorim. Trabalho artístico da criança e do adolescente: valores constitucionais e normas de proteção. Rev. TST, Brasília, vol. $79, \mathrm{n}^{\circ} 1$, jan/mar 2013.

OLIVA, José Roberto Dantas. O princípio da proteção integral e o trabalho da criança e do adolescente no Brasil. São Paulo: LTr, 2006a. 
ORGANIZAÇÃO INTERNACIONAL DO TRABALHO. Convenção n ${ }^{0}$ 138. Genebra: ILO, 1973. Disponível em: $<$ http://www.oitbrasil.org.br/info/download/conv_138.pdf $>$. Acesso em: 11 set. 2017.

REALE, Miguel. Direito natural/direito positivo. São Paulo: Saraiva, 1984.

REVISTA EPOCA. A imagem da hora. 2015. Disponível em: http://revistaepoca.globo.com/Epoca/0,6993,ЕPT391214-1661,00.html. Acesso em: 18 maio 2017.

SARLET, Ingo Wolfgang. A eficácia dos direitos fundamentais: uma teoria geral dos direitos fundamentais na perspectiva constitucional. 12 ed. rev. atual e ampl. Porto Alegre: Livraria do Advogado Editora, 2015.

SILVA, Sofia Vilela de Moraes e. Trabalho Infantil: aspectos sociais, históricos e legais. Revista Eletrônica Multidisciplinar: Olhares plurais, v. 19, n. 1, 2009.

SUSSEKIND, Arnaldo et al. Instituições de direito do trabalho. $19^{\mathrm{a}}$ ed. atual. São Paulo: LTR, 2000, vol. 2.

TRIBUNAL SUPERIOR DO TRABALHO. TST se prepara para julgar processo de trabalho infantil artístico no SBT. Disponível em: http://www.tst.jus.br/noticias//asset_publisher/8 9Dk/content/tst-se-prepara-para-julgar-processo-de-trabalho-infantilartistico-no-sbt:. Acesso em: 20 de junho de 2017.

UOL. Lucas Lima prefere que seu filho com Sandy não siga carreira artística: "Esse meio é muito complicado". Disponível em: <http://m.blogs.ne10.uol.com.br /social1/2017/04/13/lucas-lima-prefere-que-seu-filho-com-sandy-nao-siga-carreira-artisticaesse-meio-e-muito-complicado/>. Acesso em: 20 de junho de 2017 


\title{
A RESPONSABILIDADE CIVIL NO DIREITO DE FAMILIA E ALIENAÇÃO
}

\author{
PARENTAL
}

\author{
Vivia da Conceição ${ }^{l}$ \\ Geovana da Conceição ${ }^{2}$ \\ Jonathan Cardoso Régis \\ Recebido em: 20 fev. 2019 \\ Aceito em: 05 dez. 2019
}

\section{RESUMO}

O presente trabalho tem como objeto o estudo do instituto da alienação parental e como objetivo verificar a possibilidade de responsabilização civil do genitor alienador pela prática da alienação parental. Buscou-se inicialmente fazer um apanhado do histórico sobre a família, sua origem, passando ainda pelo seu conceito. Em seguida, para uma melhor compreensão da matéria, estudou-se aspectos relacionados a alienação parental, sua definição doutrinária e legal, bem como a distinção com a síndrome da alienação parental e os efeitos dessa conduta promovidas pelo genitor alienante em relação aos filhos e ao genitor não guardião. Fez-se ainda uma abordagem sobre a responsabilidade civil resultante da alienação parental, seus reflexos quanto o dever de convivência parental. Para encerrar a pesquisa foi utilizado o método indutivo, o qual fora operacionalizado com as técnicas do referente, das categorias, dos conceitos operacionais e da pesquisa de fontes documentais, resultando em uma fonte de pesquisa para os operadores do Direito.

Palavras-chave: Família. Alienação Parental. Responsabilidade Civil.

\section{CIVIL RESPONSIBILITY IN PARENTAL LAW AND FAMILY LAW}

Abstract: The present work aims at the study of the parental alienation institute and as an objective to verify the possibility of civil liability of the alienator parent by the practice of parental alienation. It was initially sought to make a history of the family, its origin, and its concept. Then, for a better understanding of the subject, we studied aspects related to parental alienation, its doctrinal and legal definition, as well as the distinction with the parental alienation syndrome and the effects of this conduct promoted by the alienating parent in relation to their children and not guardian parent. An approach was also taken on the civil responsibility resulting from the parental alienation, its reflexes as the duty of parental coexistence. In order to close the research, the inductive method was used, which was operationalized with reference techniques, categories, operational concepts and research of documentary sources, resulting in a research source for law operators.

Palavras-chave: Family. Parental Alienation. Civil responsability.

\footnotetext{
1 Especialista em Direito Civil Avançado (Univali). Graduada em Direito (Univali). Advogada. e-mail: viviacon@brturbo.com.br

2 Professora no Curso de Direito da Universidade do Vale do Itajaí de Itajaí nas disciplinas de Direito Civil (Obrigações e Família). Direito Processual Civil e Prática Jurídica. Professora da pós-graduação em direito civil. Especialista em Direito Processual Civil. Mestre em Gestão de Políticas Públicas da Univali. Doutoranda em Ciências Jurídicas e Sociais pela UNIVALI e Advogada militante na Comarca de Itajaí na área do Direito de Família. e-mail: geovanadireitodefamilia@gmail.com
} 


\section{INTRODUÇÃO}

O presente trabalho tem por finalidade discorrer sobre a responsabilidade civil no âmbito do direito de família em razão da prática da alienação parental.

Essa reflexão tem como objetivo geral, verificar a possibilidade de responsabilização civil do genitor alienador pela prática da alienação parental e, específicos, expor o processo de evolução histórica do direito de família e parentalidade; descrever a alienação parental e a reparação dos danos e, compreender a responsabilidade civil e reparação de dano em razão da alienação parental.

Iniciou-se discorrendo sobre a família, em especial, aspectos históricos, conceito (legal e doutrinário) e suas espécies,

Assim, a família é resultante do instinto dos seres vivos, de formação espontânea, com vistas à perpetuação da espécie e considerada a unidade social mais antiga, tendo proteção constitucional e infraconstitucional, calcados pela afetividade.

Em seguida, vêm o rompimento dos laços afetivos no ambiente familiar por conta da alienação parental e a síndrome da alienação parental, esclarecendo a distinção entre esses dois institutos.

Enquanto a alienação parental encontra-se vinculada ao distanciamento entre um dos genitores e seu(s) filhos, resultado esse promovido por ideias que são incutidas, induzidas ou provocadas por algum membro da família em relação à criança e/ou adolescente, a síndrome da alienação parental é o resultado desse comportamento, despertando no filho, um sentimento de rejeição ou abandono, de desvalorização, em outras palavras, o desequilibrando emocionalmente.

$\mathrm{Na}$ parte final da pesquisa, destaca-se sobre o ilícito civil e, como consequência, a responsabilidade civil especificamente relacionada com o dever de convivência parental por conta da alienação e a reparação de danos ao genitor não guardião e ao filho, vítima daquele comportamento insidioso promovido pelo genitor alienante.

\section{VISÃO HISTÓRICA E CONCEITO DE FAMÍLIA}

Para iniciar a presente reflexão, a qual tem como enfoque principal a responsabilidade civil no direito de família e a prática da alienação parental, imprescindível traçar aspectos destacados em relação à família, parentalidade, a iniciar pela exposição quanto aos aspectos históricos da família.

Há de se ressaltar, antes de adentrar nesse pensamento voltado a família, da previsão constitucional de tutela familiar, especificada no art. 226, base da sociedade e que detém especial proteção do Estado e, em destaque o seu $\S 7^{\circ}$, em que a proteção da entidade familiar encontra-se fundada "nos princípios da dignidade da pessoa humana e da paternidade responsável [...], competindo 
ao Estado propiciar recursos educacionais e científicos para o exercício desse direito", não sendo admissível qualquer espécie de conduta coercitiva por parte de todos, sejam organismos públicos ou privados.

Aliado a isso, o $\S 8^{\circ}$ do referenciado dispositivo constitucional, afirma que compete ao Estado assegurar "a assistência à família na pessoa de cada um dos que a integram, criando mecanismos para coibir a violência no âmbito de suas relações" e, dentre esse conjunto de possibilidades de vitimização no ambiente familiar, se tem a alienação parental, a qual será abordada mais adiante.

\section{Aspectos da origem familiar}

A família, de acordo com Dias (2011,p. 27),não é uma exclusividade do ser humano, mas sim dos seres vivos, "seja em decorrência do instinto de perpetuação da espécie, seja pela verdadeira aversão que todas as pessoas têm à solidão. Tanto é assim que se considera natural a ideia de que a felicidade só pode ser encontrada a dois".

Tem-se ainda que a família, conforme asseverado por Cunha (2010) que "pode ser considerada a unidade social mais antiga do ser humano" e, que, "historicamente, mesmo antes do homem se organizar em comunidades sedentárias, constituía-se em um grupo de pessoas relacionadas a partir de um ancestral comum ou através do matrimônio".

Todos os membros da família assumiam obrigações morais entre si, sob a liderança
do ancestral comum, conhecido como "patriarca", normalmente da linhagem
masculina, símbolo da unidade da entidade social, reunindo-se em uma mesma
comunidade todos seus descendentes, os quais compartilhavam de uma identidade
cultural e patrimonial. Essas primeiras entidades familiares, unidas por laços
sanguíneos de parentesco, receberam o nome de clãs (CUNHA, 2010)

A união entre as pessoas é decorrente do que Dias (2011, p. 27) afirma ser "química biológica" e que a família "é um agrupamento informal, de formação espontânea no meio social, cuja estruturação se dá através do direito".

Desse laço inicial sanguíneo de união de pessoas, a organização primitiva das famílias, conforme Cunha (2010) e Madaleno e Madaleno (2013, p. 14), originou-se as sociedades humanas organizadas, sendo que a expressão família “surge a partir de uma dessas organizações sociais".

Ademais, de acordo com Sandri (2013, p. 33), as relações sociais e, da mesma forma, as familiares, são sustentadas pelo companheirismo e afeto, voltados no sentido em que as pessoas "dedicam suas vidas para proporcionar o bem-estar para aqueles que estão à sua volta."

Nas sociedades antigas, o predomínio estava concentrado em seu caráter matriarcal, em que as mulheres, por conta da descendência dos filhos, acabavam por estabelecer um controle, de 
alguma maneira, das questões sucessórias, sendo que dos casamentos em grupos, originou-se os matrimônios sindiásmicos (NETA, 2016, p. 30), no sentido em que, de acordo com Engels (2018), em que o homem, muito embora vivendo com uma mulher, a infidelidade e de poligamia ocasionais era um direito que lhe assistia, sendo que a dissolução do vínculo familiar era comum e os filhos pertenciam a mãe de forma exclusiva, o que explicita que a família monogâmica e patriarcal sempre entendida como sendo dominante e existente na sociedade seria equivocada, servindo apenas, segundo Neta (2016, p. 30) "para a imposição de um modelo ideológico".

$\mathrm{Na}$ Roma antiga, houve o destaque para a família patriarcal, baseada na união das pessoas "sob poder familiar do ascendente mais velho do sexo masculino, ainda vivo", sendo que tal concepção passou a ser envolvida pela igreja, pelo culto à religião, limitando-a a "uma unidade familiar compreendida pelo pai, a mãe e os filhos", promovendo a "moralidade à sociedade", conforme exposto por Madaleno e Madaleno (2013, p. 14-15) transformando o matrimônio, segundo Cunha (2010) em uma "instituição sacralizada e indissolúvel, e única formadora da família cristã, formada pela união entre duas pessoas de diferentes sexos, unidas através de um ato solene, e por seus descendentes diretos" e culminando, na concepção de Madaleno e Madaleno (2013, p. 16) no crescimento da intervenção do Estado na família.

Em seguida, por conta da Revolução Industrial, transformações vivenciadas pela sociedade humana, com o ingresso da mulher no mercado de trabalho, acabam por provocar significativas modificações na até então ordem familiar, encerrando o predomínio do caráter produtivo e reprodutivo familiar e o crescimento do vínculo afetivo, surgindo-se desse modo, uma nova concepção nas relações familiares, constituída pelos laços afetivos de amor, respeito e carinho, conforme asseveram Dias (2011, p. 27), Neta (2016, p. 39) e Madaleno e Madaleno (2013, p. 16).

Assim, visto o processo de evolução histórica da família, discorrerar-se-á brevemente seu conceito.

\section{Conceito de família}

Inicialmente há de se destacar que diversos ramos da ciência podem trazer significados distintos e específicos acerca da família, seja no direito, na antropologia ou na sociologia.

Importa observar que a legislação pátria não traz uma definição de família, a qual, encontrava-se baseada principiologicamente falando, na consanguinidade entre seus membros, pode ser conceituada como:

Lato sensu, o vocábulo família abrange todas as pessoas ligadas por vínculo de sangue e que procedem, portanto, de um tronco ancestral comum, bem como as unidas pela afinidade e pela adoção. Compreende os cônjuges e companheiros, os parentes e afins. (GONÇALVES, 2015, p. 291). 
Dias (2011, p. 27) afirma também que a família é resultado de uma construção cultura, "preexistente ao Estado e está acima do direito", a qual é disposta de uma "estruturação psíquica na qual todos ocupam um lugar, possuem uma função - lugar do pai, lugar da mãe, lugar dos filhos -, sem, entretanto, estarem necessariamente ligados biologicamente", sendo que essa formação familiar (pai, mãe e filho), de acordo com Madaleno e Madaleno (2013, p. 13) é considerada a concepção clássica, a qual, atualmente, por conta da evolução da sociedade humana e normativa, "não é a sua única estrutura", uma vez que se reconhece novos tipos de estruturação familiar, baseados não apenas na consaguinidade, mas da vinculação afetiva, resultado "de movimentos sociais realizados por diversas categorias, como o das mulheres, na luta pela igualdade de direitos, e o dos casais homoafetivos, pelo reconhecimento de suas uniões fáticas, dentre outros", conforme assevera Sandri (2013, p. 36)

Ademais, Oliveira Júnior (2017), aduz que o principal elemento caracterizador que pode, atualmente define família é o carinho, afeto, demonstrações de amor e compreensão, independentemente de seu formato.

O princípio da afetividade vem se consolidando na concepção de família, conforme leciona Pereira (2018):

[...] a família está em constante transformação e transcende, sempre, sua própria historicidade.Apesar das resistências às mudanças, elas veem acontecendo, quer gostemos ou não, queiramos ou não. E é isto que tem feito da família um lugar melhor para se viver.A família não está em desordem. Ao contrário, está cada vez melhor, mais verdadeira e mais autêntica. Todas essas inevitáveis mudanças são os frutos do afeto como valor e princípio jurídico, que se tornaram o vetor e catalisador do Direito das Famílias [...] o Direito de Família traz consigo um conteúdo moral sexual que se confronta com parlamentares religiosos que misturam Direito e religião, atravancando a pauta legislativa, e não permitindo que o Estado seja verdadeiramente laico. Mas, como a fonte do Direito não é só a lei, o Direito de Família vem se alimentando de suas outras fontes, como a jurisprudência, doutrina, princípios constitucionais e principalmente os costumes. (grifo nosso)

Gomes (1998, p. 33) conceitua "família como sendo aquele composto por um grupo fechado de pessoas, composto dos genitores e filhos, e para limitados efeitos, outros parentes, unificados pela convivência e comunhão de afetos, em uma só e mesma economia, sob a mesma direção".

Assim, foi a partir da Constituição Federal de 1988, que novas formas de famílias foram reconhecidas, além do casamento em si, levando em consideração o princípio da afetividade, que vem se consolidando quando da concepção de família, diante da evolução não apenas legislativa, como também da sociedade humana. 


\section{O ROMPIMENTO DOS LAÇOS FAMILIARES: A ALIENAÇÃO PARENTAL}

$\mathrm{O}$ art. $5^{\circ}$ do Estatuto da Criança e do Adolescente - ECA estabelece que "nenhuma criança ou adolescente será objeto de qualquer forma de negligência, discriminação, exploração, violência, crueldade e opressão, punido na forma da lei qualquer atentado, por ação ou omissão, aos seus direitos fundamentais", tal dispositivo tem íntima relação com a normatização que entrou em vigor estabelecida pela Lei $n^{\circ} 12.318 / 2010$.

A referida norma legal acima especificada, passou a dispor acerca da alienação parental, cuja definição legal e doutrinária, os sujeitos envolvidos nessa relação, suas características e reflexos promovidos às crianças e aos adolescentes serão abordados a seguir.

\section{Conceito de alienação parental}

Em primeiro lugar, importa observar que a alienação parental corresponde, em síntese, ao distanciamento entre genitor e seu(s) filho(s), distanciamento este originado pelo induzimento, manipulação, ódio ou provocação de uma membro da família em relação à criança e/ou adolescente, ou seja, acaba por proporcionar em decorrência dessa influência reiterada, na destruição e desmoralização da imagem do outro genitor.

Madaleno e Madaleno (2013, p. 41), afirmam que o primeiro momento em que se buscou definir a síndrome da alienação parental foi em meados da década de 1980, mais precisamente no ano de 1985, por Richard Gardner, norte americano e professor do Departamento de Psiquiatria Infantil da Universidade de Columbia, como resultado de uma experiência que o mesmo vivenciou como perito judicial.

Para Richard A. Gardner, citado por Madaleno e Madaleno (2013, p. 42), a alienação parental resultada conduta promovida pelo genitor que detém a guarda da criança e passa a incutir, programar e/ou induzir seu filho para que adote um comportamento de ódio e repúdio, de maneira injustificada, ao outro genitor, tendo por finalidade, dentre outras, "destruir os vínculos entre o menor e o pai não guardião, caracterizado, também, pelo conjunto de sintomas dela resultantes, causando, assim, uma forte relação de dependência e submissão do menor com o genitor alienante" e, tendo como reflexo proporcionar para que, decorrente o assédio sofrido, a criança, por si só, acaba contribuindo com o genitor alienante, o que estabelece uma "combinação de lavagem cerebral com contribuições da própria criança, no sentido de difamar o genitor não guardião, sem qualquer justificativa, e seu diagnóstico é adstrito aos sintomas verificados no menor".

É caracterizado, de acordo com Sandri (2013, p. 89-90), pelo “conjunto de atos pelos quais um genitor transforma a consciência de seus filhos, mediante diferentes formas e estratégias de atuação, 
com o objetivo de impedir, obstaculizar ou destruir os vínculos daquele filho com o outro genitor."

Destaca-se ainda que o próprio dispositivo estabelecido na Lei $n^{\circ} 13.431 / 2017$, a qual versa sobre o sistema de garantia de direitos da criança e do adolescente vítima ou testemunha de violência, define, de forma clara o que vem a ser ou caracterizar a alienação parental, que nada mais é do que a influência ou a distorção de diversas situações em que aquela pessoa em processo de desenvolvimento, seja criança ou adolescente, imposta pelos pais, ascendentes em linha reta ou que detenha alguma vinculação e responsabilidade para com aquele, resultando em um comportamento de exclusão, de repúdio ou até mesmo de desprezo para com o outro e, consequentemente, em macular e prejudicar o vínculo entre os envolvidos (pai/mãe e filho).

O legislador brasileiro trouxe, de forma clara e sucinta na Lei ${ }^{\circ}$ 12.318/2010, em seu art. $2^{\circ}$ em que:

Considera-se ato de alienação parental a interferência na formação psicológica da criança ou do adolescente promovida ou induzida por um dos genitores, pelos avós ou pelos que tenham a criança ou adolescente sob a sua autoridade, guarda ou vigilância para que repudie genitor ou que cause prejuízo ao estabelecimento ou à manutenção de vínculos com este. (grifo nosso)

O citado artigo especifica, de forma exemplificativa em seu parágrafo único, comportamentos ou ações do ato de alienação parental, praticados diretamente ou com o auxílio de terceiros, "além dos atos assim declarados pelo juiz ou constatados por perícia", dentre outros, a realização de "campanha de desqualificação da conduta do genitor no exercício da paternidade ou maternidade"; assim como também dificultar o exercício da autoridade parental, de contato da criança ou adolescente com genitor ou ainda do "exercício do direito regulamentado de convivência familiar" e, da mesma forma, promover falsa denúncia contra o genitor ou familiares deste, visando dificultar o acesso e convivência com os filhos, além da conduta omissiva, de forma deliberada, de "informações pessoais relevantes sobre a criança ou adolescente, inclusive escolares, médicas e alterações de endereço".

A respeito, Neta (2016, p. 103), leciona:

[...] com a prática da alienação, o genitor guardião impede o pleno exercício dos deveres parentais pelo outro genitor, em claro prejuízo aos interesses dos filhos [...] A alienação fere violentamente a esfera individual da criança e do adolescente, que são considerados sujeitos de direito na nova ordem constitucional, e coloca em risco a saúde emocional e psíquica dos mesmos [...]

Também chamada de implantação de falsas memórias, a alienação parental é, desde sempre, uma prática usada de forma irresponsável e recorrente, quando da separação, em que, o cônjuge pelo inconformismo ou a não superação da ruptura da vida conjugal, aliado ao sentimento de raiva, rejeição, nasce o sentimento de vingança, a qual, em inúmeras situações, resulta pela adoção de um comportamento de descrédito, desmoralização ou até mesmo de destruição do ex-cônjuge ou 
companheiro (DIAS, 2011, p. 462).

Exposto resumidamente o conceito de alienação parental, resultante da influência de um dos genitores (guardião) no induzimento e na lavagem cerebral dos filhos quando da separação, levando no afastamento do cônjuge não guardião, passa-se a seguir destacar a síndrome da alienação parental.

\section{A síndrome da alienação parental}

Importa destacar, segundo Fonseca (2009) que enquanto a alienação parental é o meio ou a forma proporcionada pelo genitor guardião, a Síndrome da Alienação Parental - SAP, trata-se do resultado, do efeito gerado, sorvido pelo filho, ou seja, uma relação de causa-efeito, importando no comportamento psicossocial do sujeito, nesse caso o filho influenciado sendo tratada como uma patologia.

A SAP resulta das separações judiciais e, por consequência, das disputas entre os pais pela guarda de seus filhos e, esses processos de separação, acabam por "despertar sentimentos de traição, rejeição, abandono e angústia - quando surge o medo de não ter mais valor para o outro", em outras palavras, uma espécie de abuso emocional (MADALENO E MADALENO, 2013, p. 41).

Rosa (2012, p. 150), afirma que:

A síndrome da alienação parental se caracteriza pelo fato de um dos pais, avós ou os que tenham a criança sob sua autoridade ou guarda, para atingir o outro, como meio de vingança ou mesmo por algum desequilíbrio emocional, em virtude de separação, por incompatibilidade de ideias, por raiva, ciúmes, etc., passar a manipular a mente da criança, procurando caracterizar o outro, objeto de sua vingança, como um ser ameaçador, que lhe faz mal, que lhe agredi de algum forma, seja psíquica ou fisicamente. Na maioria dos casos, a criança acredita mesmo estar sendo vitima de algum abuso, inclusive sexual o que para ela traz consequências devastadoras, interferindo no seu caráter, na sua personalidade, na sua visão de mundo e, na perspectiva em relação ao outro, na sua confiança em si e no próximo, fazendo com ela repudie aquele que está sendo alvo dessas ideias caluniosas, dificultando-lhe a convivência.

Em outras palavras, a SAP é resultado do rompimento dos laços conjugais, onde o genitor guardião, imbuído de um sentimento de vingança, passa a despertar uma diversidade de barreiras e de falsas memórias na manutenção do contato entre o genitor não guardião e os filhos, assim como também acaba refletindo em toda extensão da família do genitor alienado, passando a "ser privada da convivência com aquela criança/adolescente, o que torna ainda mais danosa tal prática” (NETA, 2016, p. 99-101).

Gardner (2018) asseverou que a prática da alienação pode ser equivalente a uma espécie de abuso, uma vez que,

É importante notar que a doutrinação de uma criança através da SAP é uma forma de abuso - abuso emocional - porque pode razoavelmente conduzir ao enfraquecimento 
progressivo da ligação psicológica entre a criança e um genitor amoroso. Em muitos casos pode conduzir à destruição total dessa ligação, com alienação por toda a vida. Em alguns casos, então, pode ser mesmo pior do que outras formas de abuso - por exemplo: abusos físicos, abusos sexuais e negligência [...]

Paiva e Siqueira (2015, p. 36) destacam que os genitores "exercem forte influência na formação psíquica de seus filhos haja vista que a construção da personalidade do indivíduo se inicia na sua infầncia, especificamente nos primeiros anos de vida."

Diante disso, nota-se que essa influência negativa dos pais em relação aos filhos acaba por prejudicar o processo de formação da criança e do adolescente, os quais se encontram em desenvolvimento físico e psíquico, fundado no texto constitucional e do Estatuto da Criança e do Adolescente - ECA, sempre em observância e respeito à dignidade da pessoa humana, assim como de uma convivência familiar sadia, direito fundamental de todos e, em especial, da pessoa em desenvolvimento.

\section{Efeitos da alienação parental na criança ou adolescente}

Conforme previsão disposta no ECA, há em seus artigos iniciais elementos que afirmam a realidade legislativa brasileira no que tange a proteção a criança e do adolescente, a qual não é recente, são quase três décadas buscando estabelecer uma cultura de tutela e proteção ao processo de desenvolvimento sadio dessas pessoas, em que, sinteticamente, gozam de todos os direitos fundamentais inerentes à pessoa humana, sem que ocorra prejuízo da proteção integral, garantindo a estes, seja por meio legal ou de outra forma, "todas as oportunidades e facilidades, a fim de lhes facultar o desenvolvimento físico, mental, moral, espiritual e social, em condições de liberdade e de dignidade", conforme reza seu art. $3^{\circ}$.

Otero e Verdeiro (2018, p. 200) destacam que por força do comportamento doentio de um dos pais, estes passam a "manipular a memória da criança, inclusive com lavagem cerebral para que ela evite o outro genitor, tem-se o distanciamento deste e do filho", gerando dessa forma, o abandono afetivo, que pode ser observado e destacado no art. $3^{\circ}$ da Lei n. 12.318/2010 em que a prática da alienação parental viola o direito fundamental das pessoas em desenvolvimento, quais sejam crianças e adolescentes, da "convivência familiar saudável", prejudicando a "realização de afeto nas relações com genitor e com o grupo familiar" e, estabelecendo "abuso moral contra a criança ou o adolescente e descumprimento dos deveres".

Exposta a concepção e noção macro, mesmo que de forma breve, quanto a síndrome da alienação parental, passe-se a seguir para análise quanto a responsabilização decorrente da violação do dever de convivência parental. 


\section{A RESPONSABILIDADE CIVIL PELA VIOLAÇÃO DO DEVER DE CONVIVÊNCIA}

\section{PARENTAL}

Visto os aspectos destacados e pontuais referente a família, seu amparo legal, as relações de afeto e a alienação parental, passa-se a discorrer sobre a responsabilidade pela violação do dever de convivência parental.

\section{Da responsabilidade civil}

Presente no Código Civil brasileiro tem-se a responsabilidade civil, a qual, segundo previsão no art. 927, em decorrência do ato ilícito, disposto nos artigos 186 e 187, há a obrigação na reparação do dano se dá aquele que por ato ilícito, gerar dano a outrem, destacando-se que, tal obrigação reparatória, "independentemente de culpa, nos casos especificados em lei, ou quando a atividade normalmente desenvolvida pelo autor do dano implicar, por sua natureza, risco para os direitos de outrem", conforme estabelecido no parágrafo único do art. 927.

Gonçalves (2013, p. 41) traz que a origem da expressão responsabilidade, vem do latim respondere, significando a "ideia de segurança ou garantia da restituição ou compensação do bem sacrificado. Teria assim, o significado de recomposição, de obrigação de restituir ou ressarcir".

Coelho (2012, p. 171), assevera que:

A responsabilidade civil é a obrigação em que o sujeito ativo pode exigir o pagamento de indenização do passivo por ter sofrido prejuízo imputado a este último. Classificase como obrigação não negocial, porque sua constituição não deriva de negócio jurídico, isto é, de manifestação de vontade das partes [...]

Gonçalves (2013, p. 20) afirma ainda que há a possibilidade da responsabilidade promover a violação de normas jurídicas, assim como também morais, as quais podem ser analisadas isoladas ou simultaneamente, dependendo da forma em que a infração é praticada e, diante disso, o “campo moral é mais amplo do que o do direto, pois só se cogita da responsabilidade jurídica quando há prejuízo", revelando-se quando da ocorrência do cometimento infracional da norma jurídica que resulte efeito danoso ao sujeito ou ainda à coletividade.

Em síntese, segundo Gagliano e Pamplona Filho (2014, p. 31) destacam que a obrigação resultante da responsabilidade, no campo jurídico, tem como fundamento principal a proibição de ofensa, isto é, de que a ninguém se deve lesar.

Quanto a responsabilidade civil, Sampaio (2003, p. 17) assevera que:

[...] é parte integrante do direito obrigacional, posto que consiste na obrigação que tem o autor de um ato ilícito de indenizar a vítima pelos prejuízos a ela causados. A situação amolda-se ao conceito genérico de obrigação, ou seja, o direito de que é titular o credor em face do devedor, tendo por objeto determinada prestação. No caso, assume a vítima de um ato ilícito a posição de credora, podendo, então, exigir do autor 
determinada prestação, cujo conteúdo consiste na reparação dos danos causados.

Desse modo, a responsabilidade civil "pressupõe a atividade danosa de alguém que, atuando a priori ilicitamente, viola uma norma jurídica preexistente (legal ou contratual), subordinando-se, dessa forma, às consequências do seu ato", qual seja, o obrigação de reparar o dano gerado (GAGLIANO E PAMPLONA FILHO, 2014, p. 36) e, tendo como pressupostos para a sua configuração, a conduta omissiva ou comissiva, o nexo de causalidade, bem com a culpa ou dolo do agente e, consequentemente, o dano gerado.

No que se refere ao dano promovido pela conduta ilícita praticada pelo agente, Gonçalves (2013, p. 362) destaca que este é resultado da lesão de qualquer bem jurídico e nesse encontra-se inserido o dano moral, importando, "para quem sofre, no mínimo algum desconforto ou dissabor" (COELHO, 2012, p. 273)

Para Zannini (1993, p. 287), o dano moral vem a ser o sofrimento gerado à vítima, o abalo psicológico, o "prejuízo ou dano a interesses não relacionados ao patrimônio causados pelo evento prejudicial, o seja, pelo fato ou ato ilícito".

Os danos, de acordo com Coelho (2012, p. 194), "mesmo os morais, quase sempre se compensam em dinheiro. É pecuniária a maioria das obrigações de indenizar nascidas da responsabilidade civil" e, ainda, a indenização decorrente do dano moral é "uma compensação pecuniária por sofrimentos de grande intensidade, pela tormentosa dor experimentada pela vítima em alguns eventos danosos", sendo tal compensação com vista a minimizar a dor sofrida pela vítima, dentre estes, a resultante da alienação parental.

Gonçalves (2013, p. 384-386) afirma que o dano moral não seria a angústia ou a dor propriamente dita ou a humilhação sofrida pela vítima, o desgosto, uma vez que esse complexo de sofrimento vivenciado pelo evento danoso é "o conteúdo, ou melhor, a consequência do dano", o qual acaba por influenciar e interferir, "intensamente no comportamento psicológico do indivíduo, causando-lhe aflições, angústia e desequilíbrio em seu bem-estar”.

Quanto a indenização, esta será medida em conformidade com a extensão do dano, segundo o que estabelece o art. 944 do Código Civil, com destaque à observância do parágrafo único do referenciado artigo, quanto a aplicação do princípio da proporcionalidade entre a "gravidade da culpa e o dano", cabendo ao magistrado a redução, se for o caso, de forma equitativa/equilibrada, a indenização.

Dito isso, passa-se a seguir traçar aspectos da responsabilidade civil por conta da alienação parental. 


\section{Da reparação civil como resultado da alienação parental}

Importante iniciar afirmando que as relações parentais são norteadas pelos preceitos e princípios impostas pela Constituição Federal de 1988, “conformadores do Direito de Família, quais sejam, o princípio da dignidade da pessoa humana, da solidariedade, da igualdade, [...] da afetividade, da convivência familiar", e sempre primando pelo melhor interesse da criança e do adolescente, sendo que tais princípios detém a imposição aos "membros de uma família uma série de direitos-deveres, que devem ser exercidos de modo a garantir a plena efetividade da dignidade de todos aqueles que participam das relações familiares", sendo que tais deveres, uma vez não observados e cumpridos, se constituem de ilícitos civis, tendo por consequência, a possibilidade de responsabilização e sanção (NETA, 2016, p. 165-166).

Desse modo, a previsão disposta no art. 603 da Lei no 12.318/2010 estabelece sanções aplicáveis aos alienadores, tendo por finalidade fazer cessar os danos gerados pela síndrome de alienação parental e sem a ocorrência de prejuízo da responsabilidade civil, sendo que a tipificação da conduta é demonstrada quando da dificuldade existente de convivência da criança/adolescente com o genitor e poderão ser aplicadas de forma isolada ou cumulativamente.

Em outras palavras, de acordo Souza (2018), para que se tenha a configuração da responsabilidade civil no âmbito familiar, em especial, por conta da alienação parental, basta "que seja reconhecido o ato ilícito, o que não será uma característica difícil de ser observada nos litígios que envolvem a SAP, não necessitando de norma jurídica especifica".

Asseveram Madaleno e Madaleno (2013, p. 117-118) que,

[...] A indenização por dano moral ou material é admitida pelo ordenamento jurídico brasileiro e tem especial referencia na Lei da Alienação Parental, diante dos notórios prejuízos de ordem moral e material causados pela propositada e injustificada alienação dos filhos ao outro progenitor, e até mesmo em relação aos avós ou irmãos da criança ou adolescente alienado. É indenizável o sofrimento psíquico ou a frustração pela incerteza anímica do progenitor não guardião pela perda da relação paterno-filial com a ruptura do regime de visitas e pelo total desrespeito ao direito de comunicação fundamental nos vínculos de filiação. $O$ dano moral reclama a demonstração do nexo causal entre a atitude do alienante e os prejuízos morais, por

\footnotetext{
${ }^{3}$ Art. 6o ${ }^{-}$Caracterizados atos típicos de alienação parental ou qualquer conduta que dificulte a convivência de criança ou adolescente com genitor, em ação autônoma ou incidental, o juiz poderá, cumulativamente ou não, sem prejuízo da decorrente responsabilidade civil ou criminal e da ampla utilização de instrumentos processuais aptos a inibir ou atenuar seus efeitos, segundo a gravidade do caso:

I - declarar a ocorrência de alienação parental e advertir o alienador;

II - ampliar o regime de convivência familiar em favor do genitor alienado;

III - estipular multa ao alienador;

IV - determinar acompanhamento psicológico e/ou biopsicossocial;

V - determinar a alteração da guarda para guarda compartilhada ou sua inversão;

VI - determinar a fixação cautelar do domicílio da criança ou adolescente;

VII - declarar a suspensão da autoridade parental.

$[\ldots]$
}

Ponto de Vista Jurídico | Caçador | v.8 | nº 2 | p. 38-54 | jul./dez. 2019 
abalo psíquico sofrido pelo progenitor alienado e pela criança ou o adolescente.

Ademais, o art. 227 da Carta Constituinte de 1988 traz que a família, dentre outros atores sociais tem a responsabilidade em zelar e garantir à criança, ao adolescente e ao jovem, com prioridade absoluta, não apenas o direito à vida, como a plenitude para seu desenvolvimento, de direitos sociais dispostos no texto constitucional e, dentre outros, o direito à convivência familiar, a qual "implica em presença, em cuidado em assistência material e moral. Significa, pois, ser pai e/ou mãe, no profundo sentido dessas palavras" (NETA, 2016, p. 167). Diante disso, em havendo o descumprimento dessa obrigação parental de zelo, cuidado e de convivência para com os filhos, tem-se a aplicação da responsabilidade civil.

A já mencionada Lei $\mathrm{n}^{\mathrm{o}}$ 12.318/2010 traz claramente o reconhecimento da responsabilização civil do genitor alienante pelo dano moral resultante da alienação parental, ante ao disposto no art. $3^{\circ}$ que traz a conduta abusiva e ilícita proposta por esse, gerando o que o texto de lei especifica como abuso moral, em que acaba por prejudicar, segundo asseverado por Costa (2012, p. 20) "a realização de afeto nas relações com genitor e com o grupo familiar", sendo que o maior dano proporcionado por essa conduta é aquele em que "o alienante afasta o menor do convívio do outro genitor, causa inúmeros prejuízos tanto para a criança quanto para o genitor alienado. Assim, as vítimas da alienação parental são os menores e os genitores alienados" e, pelo ato ilícito gerado, tem-se o dever de indenizar.

Douglas Freitas citado por Ohlweiler (2018), assevera quanto a ilicitude da alienação parental, a qual gera a reparação de danos morais, uma vez que tal conduta, "além de ilícita, é culpável na forma ativa, geradora de dano e, por constituir os elementos mínimos necessários para a configuração da responsabilidade civil à luz dos artigos 186, 187 e 927 do Código Civil”, impondo-se ao genitor alienador o dever de compensação ao genitor alienado, assim como também a criança e/ou ao adolescente alienado, a fim compensar moralmente pelos danos causados por aquelas ações.

Há ainda de se ressaltar que não seria qualquer espécie de conduta executada, incitada pelo alienador, passível do dever de indenizar.

Quanto à possibilidade de reparação de dano por conta da conduta do alienador em relação ao genitor alienado, foi noticiado pelo Tribunal de Justiça do Distrito Federal e Territórios - TJDFT (2016), decisão dessa natureza em que:

[...] o que se vê é um pai em busca quase que desesperada de se aproximar da filha, enquanto a mãe, por razões injustificáveis, em nada contribuiu com a plena realização do direito da filha de conviver com seu genitor. Muito pelo contrário, o que sugerem os autos é que a fragilização dos laços afetivos entre pai e filha pode ter sido potencializada pela conduta da mãe. Logo, constatada a conduta ilícita da autora, o dano moral causado ao genitor é evidente, "tendo em vista que se trata de incursão em 
seara sentimental de elevada grandeza, que é aquela na qual se hospeda a afetividade existente entre pai e filha", conclui o magistrado ao julgar improcedente o pedido formulado pela autora, e procedente o pedido contraposto do acusado, para condenar a genitora ao pagamento de indenização no valor de $\mathrm{R} \$ 1,5$ mil, a título de danos morais. (grifo nosso)

Em decisão mais recente, proferida no ano de 2018, o Tribunal de Justiça do Mato Grosso do Sul (IBDFAM, 2018), acabou por condenar o genitor alienante ao pagamento de indenização por dano moral a ex-mulher pela prática de alienação parental com a filha, por ter aquele induzido sua filha a desenvolver sentimentos negativos em relação a sua mãe, assim como também abalos psicológicos a infante e crises emocionais, havendo, por conta disso, verificação quanto a violação direta e intencional da obrigação do genitor em promover, bem como estimular uma relação positiva e harmoniosa entre a criança e seu outro genitor.

Há de se fazer menção ainda quanto a elemento caracterizador quanto a síndrome da alienação parental, em especial, quanto a indenização pelo dano gerado, a imprescindibilidade de "realização de estudos psicossociais com a criança, a fim de permitir uma avaliação detalhada do seu estado psíquico", no que se refere a demonstração, ou não, "de um processo de destruição, de desmoralização, de descrédito da figura paterna" (TJDFT, 2017).

Sendo assim, diante do que fora até o presente momento apresentado, nota-se que o genitor alienante, ao agir ilicitamente e em afronta à disposição legal, adotando comportamento típico e caracterizador de alienação parental, impõem-se a esse o dever de indenizar por conta do cometimento de ato ilícito, em conformidade com o art. 927 c/c o art. 186 do Código Civil, não podendo esquecer da primazia da dignidade da pessoa humana da criança e do adolescente alienado e garantindo a este a convivência harmônica com o outro genitor (alienado e não guardião).

\section{CONSIDERAÇÕES FINAIS}

A presente pesquisa teve como objetivo estudar a responsabilidade civil no direito de família e a alienação parental.

Para o desenvolvimento lógico, o trabalho foi subdividido em três pontos principais.

O primeiro tratou do histórico da família, seu conceito e espécies compreendidas e reconhecidas constitucionalmente ou pelos tribunais pátrios.

Assim, a família, considerada a unidade social mais antiga, decorre da união, da formação espontânea e não é uma exclusividade do ser humano, mas sim do instinto dos seres vivos, tendo por finalidade a perpetuação da espécie e tutelada constitucional e infraconstitucionalmente.

Ressalta-se que a tutela estabelecida à família no texto constitucional, encontrada mais especificamente em seu art. 226, tendo proteção especial do Estado e baseada nos princípios da 
paternidade responsável e da dignidade da pessoa humana, aliada a afetividade mútua.

Em seu aspecto histórico, a família detinha um ancestral em comum ou aquele grupo de pessoas estaria reunido por conta do matrimônio e, que os membros da família passavam a assumir obrigações morais e sob a condução do patriarca.

Ademais, as relações familiares devem ser sustentadas pelo mútuo sentimento de afeto, respeito, companheirismo, a fim de proporcionar e garantir o bem-estar daqueles entes.

O período pós-revolução industrial proporcionou mudanças a sociedade humana e, por consequência, adequações a nova realidade que passou a ser estabelecida, como o ingresso da mulher no mercado de trabalho, o crescimento do vínculo afetivo e a institucionalização do casamento motivado e protegido pelo Estado.

Quanto a seu conceito, observa-se que atualmente, seus membros não são compostos tão somente pelos laços de sangue, pela descendência, mas também pela adoção e afinidade.

Além da previsão constitucional de proteção à família, há ainda, dentre as responsabilidades deste, assim como da sociedade, da comunidade e do Estado, assegurar à criança e ao adolescente, prioridade absoluta a seu processo de desenvolvimento físico, psíquico, moral, espiritual e assegurando a estes seguros de qualquer espécie de negligência, exploração, crueldade ou violência.

E é nesse sentido que se analisa a alienação parental, a qual consiste no distanciamento do genitor não guardião de seu filho, por conta da adoção de um comportamento influenciador proposto pelo genitor guardião ou familiares, o qual acaba, de forma injustificada, por induzir, manipular e provocar ódio e desmoralização para com o outro, destruindo os vínculos existentes naquela relação.

Atualmente, a Lei $n^{\circ} 12.318 / 2010$, assim como também a Lei $n^{\circ} 13.431 / 2017$ traz, de forma clara e direta uma definição legal acerca da alienação parental, consistente na interferência ou influência psicológica no processo de formação do infante, promovendo a distorção de informações impostas pelos pais ou familiares que detenham a guarda do infante.

A Lei $n^{0}$ 12.318/2010 estabelece ainda, uma vez caracterizada a alienação parental, independente da responsabilização civil e criminal, o juiz poderá, de acordo com a gravidade do fato, adotar, isolada ou cumulativamente, diversas medidas, partindo da advertência, chegando na situação extrema da suspensão da autoridade parental.

Conforme disposto na pesquisa, desse comportamento adotado de alienação parental, resultante de um ato ilícito, lesando direitos, conduta essa promovida por parte do genitor guardião, tem-se a responsabilização deste pela reparação de danos, não apenas ao genitor não guardião, como também a criança ou adolescente alienada, uma vez que aqui estão sendo violados direitos garantidos pelo texto constitucional. 
Nesse aspecto, visando cessar os danos gerados, a legislação pátria, mais especificamente a Lei $n^{0}$ 12.318/2010, prevê uma diversidade de sanções passíveis de ser aplicadas ao alienador e sem que promova prejuízo na busca pela responsabilidade civil gerada e a consequente reparação de danos.

Denota-se que as características decorrentes da alienação parental, uma vez reconhecida a conduta ilícita, em que gera prejuízo de natureza material e/ou moral intencionalmente exercida pelo genitor alienante em detrimento ao outro genitor (não guardião) ou até extensivamente aos demais membros da família alienada, sendo que a indenização se dá pelo sofrimento, frustração, sequelas, ausência de afeto e pelo rompimento de perda dessa relação genitor-filho a qual é gerada pelo abalo psíquico sofrido não apenas pelo genitor não guardião, como também à criança e/ou adolescente alienado

\section{REFERÊNCIAS}

BRASIL. Constituição da República Federativa do Brasil. São Paulo: Saraiva, 2018.

. Lei n ${ }^{\circ} 8.069$, de 13 de julho de 1990. Dispõe sobre o Estatuto da Criança e do Adolescente e dá outras providências. Brasília, DF, 16 jul. 1990. Disponível em: $<\mathrm{http}$ ://www.planalto.gov.br/ccivil_03/leis/18069.htm>. Acesso em: 23 set. 2018.

. Lei $n^{\circ}$ 10.406, de 10 de janeiro de 2002. Institui o Código Civil. Brasília, DF, 10 jan. 2002. Disponível em: $<$ http://www.planalto.gov.br/ccivil_03/leis/2002/110406.htm>. Acesso em: 23 set. 2018.

. Lei $\mathrm{n}^{\mathrm{o}} 12.318$, de 26 de agosto de 2010. Dispõe sobre a alienação parental e altera 0 art. 236 da Lei $n^{\circ}$ 8.069, de 13 de julho de 1990. Brasília, DF, 26 ago. 2010. Disponível em: $<$ http://www.planalto.gov.br/ccivil_03/_ato2007-2010/2010/lei/112318.htm>. Acesso em: 23 set. 2018.

. Lei $\mathrm{n}^{\mathrm{o}} 13.431$, de 04 de abril de 2017. Estabelece o sistema de garantia de direitos da criança e do adolescente vítima ou testemunha de violência e altera a Lei no 8.069, de 13 de julho de 1990 (Estatuto da Criança e do Adolescente). Brasília, DF, 04 abr. 2017. Disponível em: $<$ http://www.planalto.gov.br/ccivil_03/_ato2015-2018/2017/lei/L13431.htm>. Acesso em: 23 set. 2018.

COELHO, Fábio Ulhoa. Curso de direito civil - obrigações: responsabilidade civil. v. 2.5 ed. São Paulo: Saraiva, 2012 (E-book).

COSTA, Mariana Andrade da. A responsabilidade civil por alienação parental.Escola da Magistratura do Estado do Rio de Janeiro. Rio de Janeiro, 2012, p. 20. Disponível em: $<$ http://www.emerj.tjrj.jus.br/paginas/trabalhos_conclusao/2semestre2011/trabalhos_22011/Mariana AndradedaCosta.pdf $>$. Acesso em: 06 out. $201 \overline{8}$.

CUNHA, Matheus Antônio da. O conceito de família e sua evolução histórica. Portal Jurídico Investidura, Florianópolis/SC, 27 Set. 2010. Disponível em:<investidura.com.br/bibliotecajuridica/artigos/historia-do-direito/170332-o-conceito-de-familia-e-sua-evolucao-historica $>$. Acesso em: 29 set. 2018.

DIAS, Maria Berenice. Manual de direito das famílias. 8. ed. rev. e atual. São Paulo: Editora Revista dos Tribunais, 2011.

DISTRITO FEDERAL. Tribunal de Justiça. Alienação parental gera indenização por danos morais.

$<$ https://www.tjdft.jus.br/institucional/imprensa/noticias/2016/janeiro/alienacao-parental-gera- 
indenizacao-por-danos-morais>. Acesso em: 06 out. 2018.

DISTRITO FEDERAL. Tribunal de Justiça. Acórdão n. 1039121, 20160510046647APC. Relator: Des. Carlos Rodrigues. $6^{a}$ Turma Cível, d.j: 14/06/2017, Publicado no DJE: 22/08/2017, p. 647/690. Disponível em: $<$ https://pesquisajuris.tjdft.jus.br/IndexadorAcordaos-web/sistj>. Acesso em: 06 out. 2018.

ENGELS, Friedrich. A origem da família, da propriedade privada e do Estado. Disponível em:

$<$ http://www.dhnet.org.br/direitos/anthist/marcos/hdh_engels_origem_propriedade_privada_e stado.pdf $>$. Acesso em: 30 set. 2018.

FONSECA. Priscila Maria Pereira Corrêa da. Síndrome da Alienação Parental. In: Revista do Centro de Apoio Operacional Cível, Ministério Público do Estado do Pará, Centro de Apoio Operacional Cível. Belém: M. M. Santos Editora, 2009. Ano 11, n. 15, p. 49-60.

GAGLIANO, Pablo Stolze. PAMPLONA FILHO, Rodolfo. Novo curso de direito civil: responsabilidade civil. v. 3. 12 ed. rev. e atual. São Paulo: Saraiva, 2014 (E-book).

GARDNER, Richard A. O DSM-IV tem equivalente para o diagnóstico de síndrome da alienação parental (SAP)? Disponível em: <http://www.alienacaoparental.com.br/textossobre-sap-1/o-dsm-iv-tem-equivalente>. Acesso em: 30 set. 2018.

GOMES, Orlando. Direito de Família. 11 ed. Rio de Janeiro: Forense, 1998.

GONÇALVES, Carlos Roberto. Direito Civil brasileiro: responsabilidade civil. v. 4.8 ed. São Paulo: Saraiva, 2013.

.Direito civil esquematizado. v. 3.Coord. Pedro Lenza. 2 ed. São Paulo: Saraiva, 2015.

IBDFAM. Instituto Brasileiro de Direito de Família - IBDFAM. Homem que praticava alienação parental é condenado a pagar danos morais para ex-esposa. Disponível em: $<$ http://www.ibdfam.org.br/noticias/6591/Homem+que+praticava+alienação+parental+é+conde nado+a+pagar+danos+morais+para+ex-esposa $>$. Acesso em: 06 out. 2018.

MADALENO, Ana Carolina Carpes. MADALENO, Rolf. Síndrome da alienação parental: a importância de sua detecção com seus aspectos legais e processuais. Rio de Janeiro: Forense, 2013.

NETA, Ainah Hohenfeld Angelini. Convivência parental e responsabilidade civil: indenização por abandono afetivo. Curitiba: Juruá, 2016.

OLIVEIRA JÚNIOR, Isaias Batista de. Em cartaz: a formação docente e as representações de famílias organizadas em modelos não convencionais. RPGE- Revista online de Política e Gestão Educacional, v.21, n.2, p. 542-562, maio-ago/2017. Disponível em: $<\mathrm{https}$ //www.researchgate.net/publication/318830903_Em_cartaz_a_formacao_docente_e_as_repre sentacoes de familias organizadas em modelos nao convencionais $>$. Acesso em: 30 set. 2018.

OTERO, Cleber Sanfelici. VERDERIO, Olivia. A responsabilidade dos pais pelo abandono afetivo dos filhos e o prejuízo moral para eles em dignidade. $O$ problema do abandono afetivo subsequente à (síndrome da) alienação parental. Direito de família e das sucessões I [Recurso eletrônico on-line] organização CONPEDI/ UFBA. Coordenadores: José Sebastião de Oliveira; Cláudia Mara A. Rabelo Viegas; Ilton Garcia da Costa; Valéria Silva Galdino Cardin - Florianópolis: CONPEDI, 2018.

OHLWEILER, Débora Dihl. A responsabilidade civil pela conduta de alienação parental. Disponível em: $<$ https://ddoadv.jusbrasil.com.br/artigos/314226554/a-responsabilidade-civil-pelaconduta-de-alienacao-parental>. Acesso em: 06 out. 2018.

PAIVA, Caroline Zanetti. SIQUEIRA, Dirceu Pereira. A contemporaneidade do direito de família e suas possíveis fragilidades: alienação parental avanço ou retrocesso? In: Direito de família e sucessões [Recurso eletrônico on-line] organização CONPEDI/UFMG/ FUMEC/Dom Helder Câmara; coordenadores: Luciana Costa Poli, Valéria Silva Galdino Cardin, Tereza Cristina Monteiro Mafra - Florianópolis: CONPEDI, 2015. 
PEREIRA, Rodrigo da Cunha. Conceito de família está cada vez mais organizado e autêntico. Consultor Jurídico - Conjur. Disponível em: $<$ https://www.conjur.com.br/2017-dez24/processo-familiar-conceito-familia-cada-vez-organizado-autentico $>$. Acesso em: 30 set. 2018.

ROSA, Graziela Matos Souza Santa. Síndrome da alienação parental ou simplesmente vingança, p. 150. Revista Letrando. v. 2. jul./dez. 2012. Disponível em: $<$ http://revistaletrando.com/revista/volume2/15.Graziela.pdf >. Acesso em: 30 set. 2018.

SAMPAIO, Rogério Marrone de Castro. Direito civil: responsabilidade civil. 3. ed. São Paulo: Atlas, 2003.

SANDRI, Jussara Schmidt. Alienação parental: o uso dos filhos como instrumento de vingança entre os pais. Curitiba: Juruá, 2013.

SOUZA, Ronaldo Ribeiro da. A responsabilidade civil por alienação parental. Disponível em: $<$ https://jus.com.br/artigos/58175/a-responsabilidade-civil-por-alienacao-parental $>$. Acesso em: 06 out. 2018.

ZANNINI, Eduardo. A. EI daño en la responsabilidad civil. 2 ed. actual. y ampl. Buenos Aires: Editorial Astrea, 1993. 